\title{
The Factors that Motivate Law Enforcement' Use of Force: A Systematic Review
}

\author{
Mariah Cowell, Christopher Corsi, Terence Johnson, and Lauren Brinkley-Rubinstein
}

\section{Highlights}

- Social-ecological framework is used to examine use of force at the individual and community level.

- We discuss recommendations for research through an equity lens that highlights community organizers.

- Interventions, trainings, and education to stop the promotion of perceived safety over justice are highlighted.

\begin{abstract}
Media attention relevant to law enforcement use of force in the last decade finally alerted the scientific community to the need for more research regarding law enforcement discretion and decision making. The purpose of this study was to synthesize the existing literature to explore the motivating factors for law enforcement use of force. This study will utilize a social-ecological framework to systematically examine factors that impact officer decisions to use force at the individual and community levels. The paper includes recommendations for research and practice through an equity lens that highlights the disparate use of force against men of color in particular. Interventions, trainings, education, and research to stop the promotion of perceived safety over justice will be highlighted.
\end{abstract}

Keywords Discretion - Law enforcement - Police · Police brutality - Social-ecological model. Use of force . Violence

\section{Introduction}

The use of force has been viewed as integral to the role of police within society, but improper use of force should be deemed as the central problem of police misconduct (Harris, 2009, p. 25). Waves of high-profile shootings of Black people in the United States from George Floyd,

Mariah Cowell

mariah_cowell@med.unc.edu

School of Social Medicine, Center for Health Equity Research, University of North Carolina at Chapel Hill, Chapel Hill, NC, USA
Breonna Taylor, Tony McDade, and countless others in 2020 to Eric Garner, Michael Brown, Walter Scott, Freddie Gray, Philando Castile, and Alton Sterling in 20142016 have been a catalyst for calls to reform policing in the United States (Spencer, Charbonneau, \& Glaser, 2016). The excessive use of force through police brutality is illustrated in the case of George Floyd in which he had an officer on his neck while three other officers watched for 8 minutes and 43 seconds, while many videos were taken by those who witnessed the murder.

Decades-old research examined the factors that impact law enforcement use of force such as situational factors, psychological variables, and organizational influences (Harris, 2009). However, there is a need for a new review of the literature after the changes in social media have allowed for increased visibility for subsequent widespread social movements, such as Black Lives Matter. In addition, much of the seminal research on motivations for police use of force strictly focus on individual characteristics by examining individual police behavior (Riksheim \& Chermak, 1993; Sherman, 1980). Similarly, existing reviews that synthesize what is known about use of force have only examined the individual attributes of a person, such as race, gender, or the specific encounter characteristics (Klahm \& Tillyer, 2010). Therefore, the primary aim of this review is to synthesize the existing literature to explore the current and multi-level understanding of the motivating factors that impact law enforcement use of force. By framing the use of force in the social-ecological model, we can characterize the multi-level factors that impact police use of force. The social-ecological model acknowledges that individual behaviors are complex and influenced by (a) individual characteristics (e.g., attitudes, values, beliefs); (b) the social aspects of life such as 


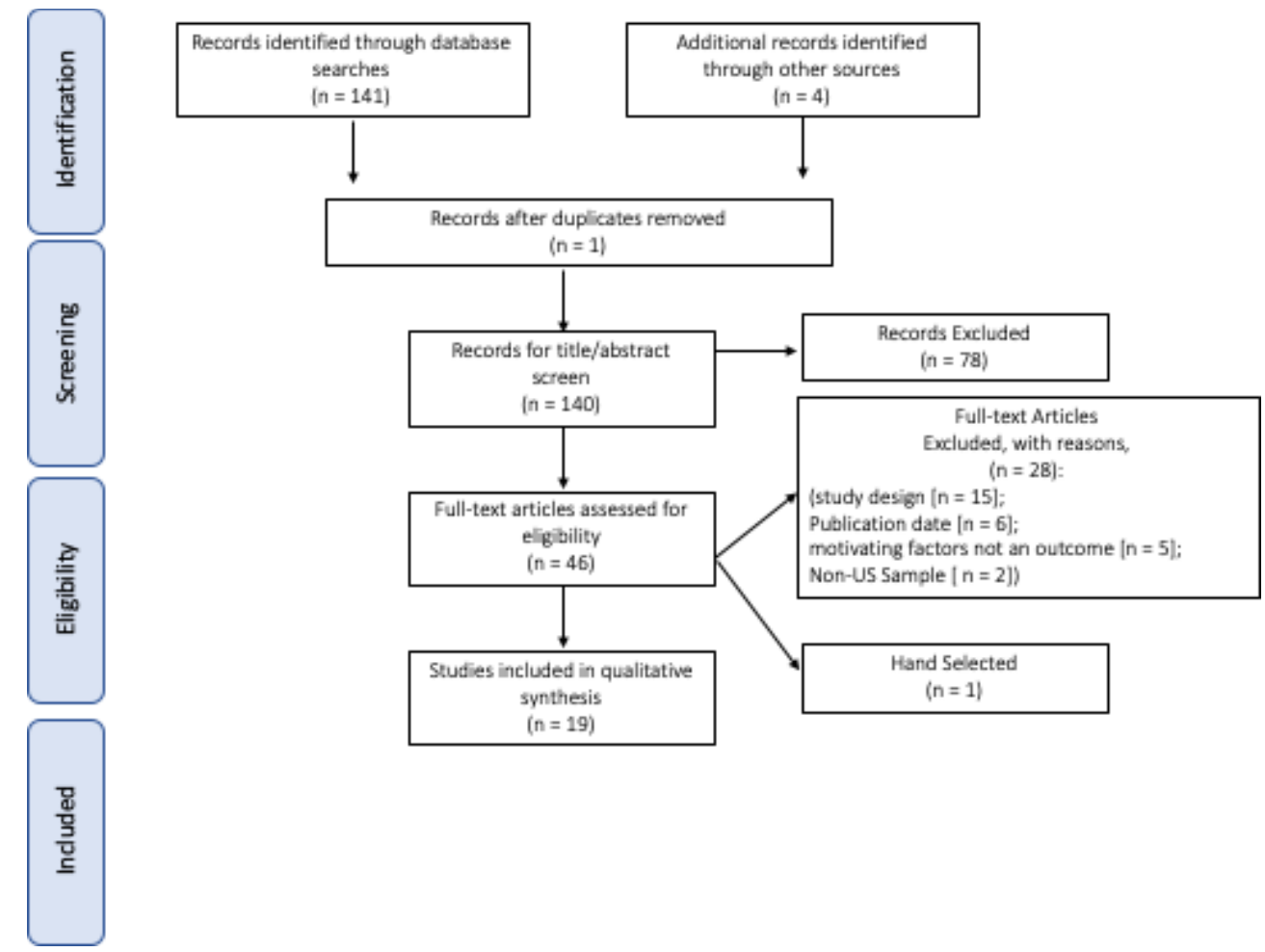

Fig. 1 Flow diagram depicting the identification, screening, and inclusion of studies

relationships, family, and social support; and (c) the community (e.g., where you live, concentration of poverty, crime, density of social or health services) (Bronfenbrenner, 1979). Moving beyond the individual allows for a more comprehensive understanding of how community, family, and social factors all intersect to create societal issues as well as influence what levers could be pulled to intervene.

\section{Methods}

We reviewed articles that examined motivations for law enforcement use of force from 2009 to 2019. This systematic review followed the guidelines described in the Cochrane Handbook (Higgins \& Green, 2018) and the Preferred Reporting Items for Systematic Reviews and Meta-Analyses (PRISMA) guidelines (Moher, Liberati, Tetzlaff, Altman, \& PRISMA Group, 2009) and has been submitted for registration with PROSPERO. Figure 1 contains a PRISMA flow diagram that outlines the identification, screening, eligibility, and inclusion process.

The research team developed standards and protocols for database searches using COVIDENCE. This included developing parameters for study inclusion and exclusion criteria, data extraction tools, data management strategies, and methods for quality assessment. The research team used two methods to identify relevant research: (a) database searches of peer-reviewed literature and (b) hand Internet searches for literature. The following databases were searched systematically for relevant research: PsycINFO, PubMed, Social Service Extracts, Social Work Abstracts, and Google Scholar (see Table 1). The search was conducted using the following search terms and related terms: law enforcement OR police AND use of force OR miscon* OR brutal* OR violence OR kill OR lethal $\mathrm{OR}$ excessive force $\mathrm{OR}$ unnecessary force $\mathrm{OR}$ improper force $\mathrm{OR}$ illegitimate force $\mathrm{OR}$ abuse of force $\mathrm{OR}$ misuse of force AND motivat* OR factors OR percep*. Each search began using the following and was used to search all databases for studies published between January 1, 2010, and September 1, 2019. This resulted in 141 articles.

Table 1 Data extraction timeline

\begin{tabular}{ll}
\hline Database & Date range \\
\hline $\begin{array}{l}\text { PsycINFO } \\
\text { Google scholar }\end{array}$ & $\begin{array}{l}\text { September 2018, last searched September 1, 2019 } \\
\text { Social service } \\
\text { extracts }\end{array}$ \\
$\begin{array}{c}\text { Social work } \\
\text { abstracts }\end{array}$ & September 2018, last searched September 1, 2019 \\
PubMed & September 2018, last searched September 1, 2019 \\
\hline
\end{tabular}


Studies were included in the review if they met the following criteria that were determined in advance: (a) empirical in their focus and examined either qualitative or quantitative data; (b) investigated the motivating factors behind law enforcement use of force; (c) published within the last ten years, 2009-2019; and (d) took place in the United States. This decision was made due to specific historical and cultural parameters of policing and mass incarceration in the United States.

Studies that did not meet the design requirements were excluded. As seen in Table 3, 141 studies were extracted for screening. One duplicate study was removed from the initial screening. Of the 140 that remained, 77 studies were deemed outside the scope of this review during the title and abstract screening based on various eligibility criteria such as publication date, outcomes, and study design. Forty-seven (47) studies were selected as eligible based on established criteria for full-text screening, of those remaining, 28 were removed during further screening due to the following: outcomes were not in line with the review aim of motivating factors $(n=5)$ and did not include empirical data $(n=6)$, and study population was not within the United States $(n=1)$. One publication was added after the initial data pull through a hand search $(n=1)$. After this final screening, 19 studies were included in the final review (Table 1).

\section{Data Extraction, Management, and Analysis}

A data extraction sheet was developed to manage the results of the 19 included studies (see Table 3). Extracted information included the citation, research question, study design, sample size, socioecological framework level, outcomes, results, conclusions, and strengths and limitations. We analyzed all 19 studies and categorized their level of analysis as (a) individual level or (b) social and community level. We defined individual level as concerned only with attitudes or demographic factors. In contrast, studies were categorized as social if they examined relationships with the suspect or within an organization or institution. Studies were categorized as community level if they focused on more structural factors such as geography, politics, or policies.

\section{Results}

\section{Study Characteristics}

\section{Research Design}

The 19 studies that were examined varied in their sample, methodology, and multi-level factors (see Tables 2 and 3). Samples for quantitative studies range from $n=101$
Table 2 Description of study methods

\begin{tabular}{lll}
\hline Qualitative methods & $n=2$ & $10.53 \%$ \\
Semi-structured interviews & $n=2$ & $10.53 \%$ \\
Quantitative methods & $n=17$ & $89.47 \%$ \\
Cross-sectional study & $n=9$ & $47.37 \%$ \\
$\quad$ Secondary data analysis & $n=5$ & $26.32 \%$ \\
Meta-analyses & $n=2$ & $10.53 \%$ \\
Systematic review & $n=1$ & $5.26 \%$ \\
Content analyses (officer reports, case files) & $n=11$ & $57.89 \%$ \\
\hline
\end{tabular}

(case files) to $n=2$ million (officer reports). The samples for the qualitative studies range from 40 to 43 officer accounts. The samples from the 19 studies that were reviewed included administrative data from officer encounters or direct officer perspectives through interviews.

\section{Social-Ecological Model Integration}

Articles were examined for the level of integration of the social-ecological model into their methodology. Two reviewers coded for the following: (a) for the incorporation of the impact of broader societal systems, such as policies or institutional racism; (b) the impact of the geographic location, community, or neighborhood on the decision to use force; (c) the impact of relationships that influence an officer's decision to use force; and (d) the attributes of an individual, such as identity or clothing, that impact an officer's decision to use force.

\section{Individual}

Of the 19 reviewed articles, almost all $(n=18 ; 95 \%)$ articles addressed the individual-level factors. The studies that focused only individual level, rather than incorporating the various systems that impact the decision to use force, found that officer gender, self-control, restraint, bias, and patrol shift were important motivating factors (see Table 3 for a complete description of the individuallevel factors) (Brandl \& Stroshine, 2012; Donner, Fridell \& Jennings, 2016; Klinger \& Brunson, 2009; Pinizzotto, Davis, Bohrer, \& Infanti, 2012). Almost a quarter (21\%) of the studies only examined the individual-level factors and completely excluded any other factors (e.g., relationships, community, policies). A little less than half (42\%; $n=8$ ) of the studies examined more than one facet of the social-ecological model (i.e., both community and social). Many of the individual-level factors focused on the officer characteristics that explain the use of force.

Social- and Community-Level Factors

Seventy four percent $(n=14)$ of studies examined some aspect of motivations that were beyond the individual. 


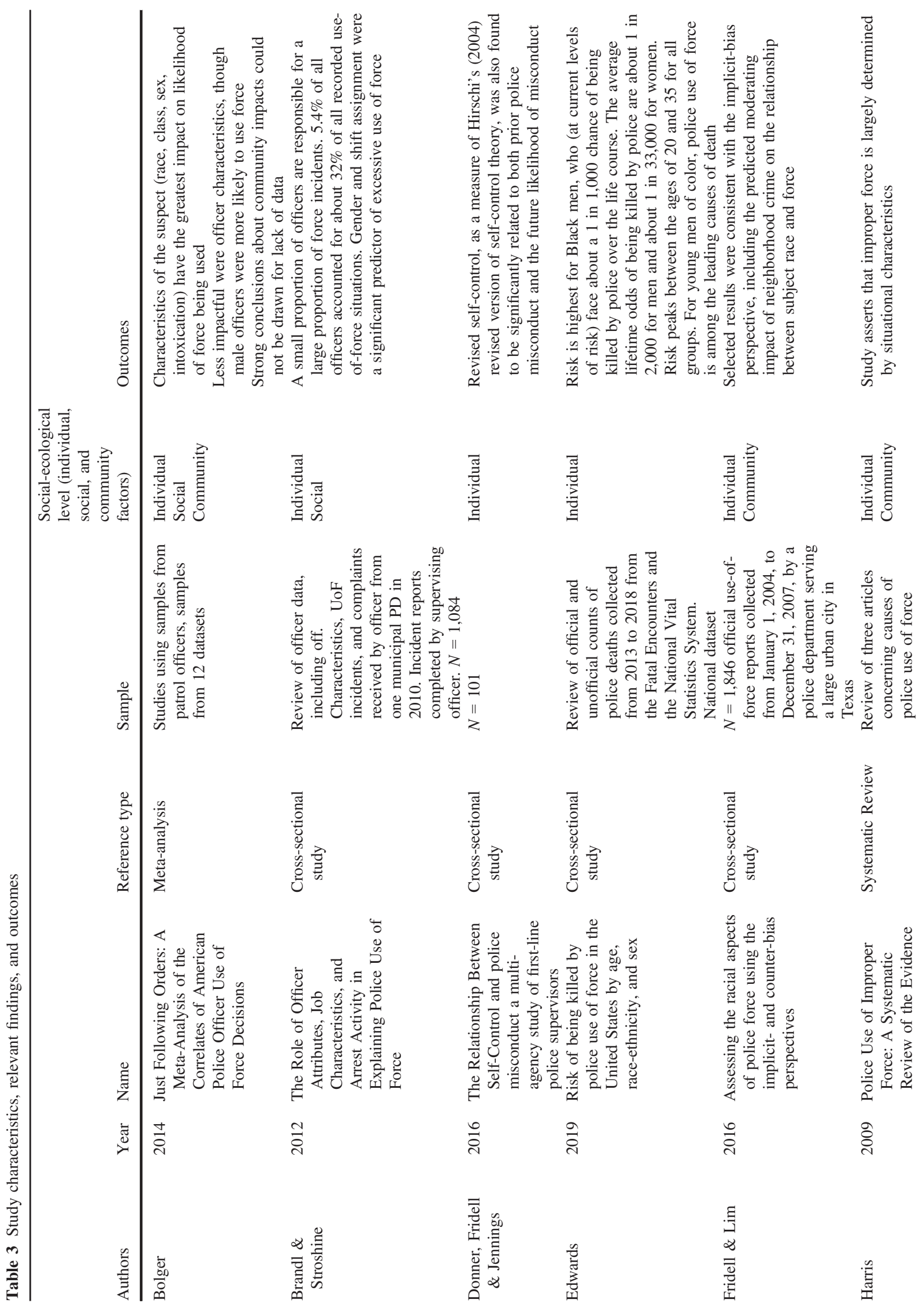




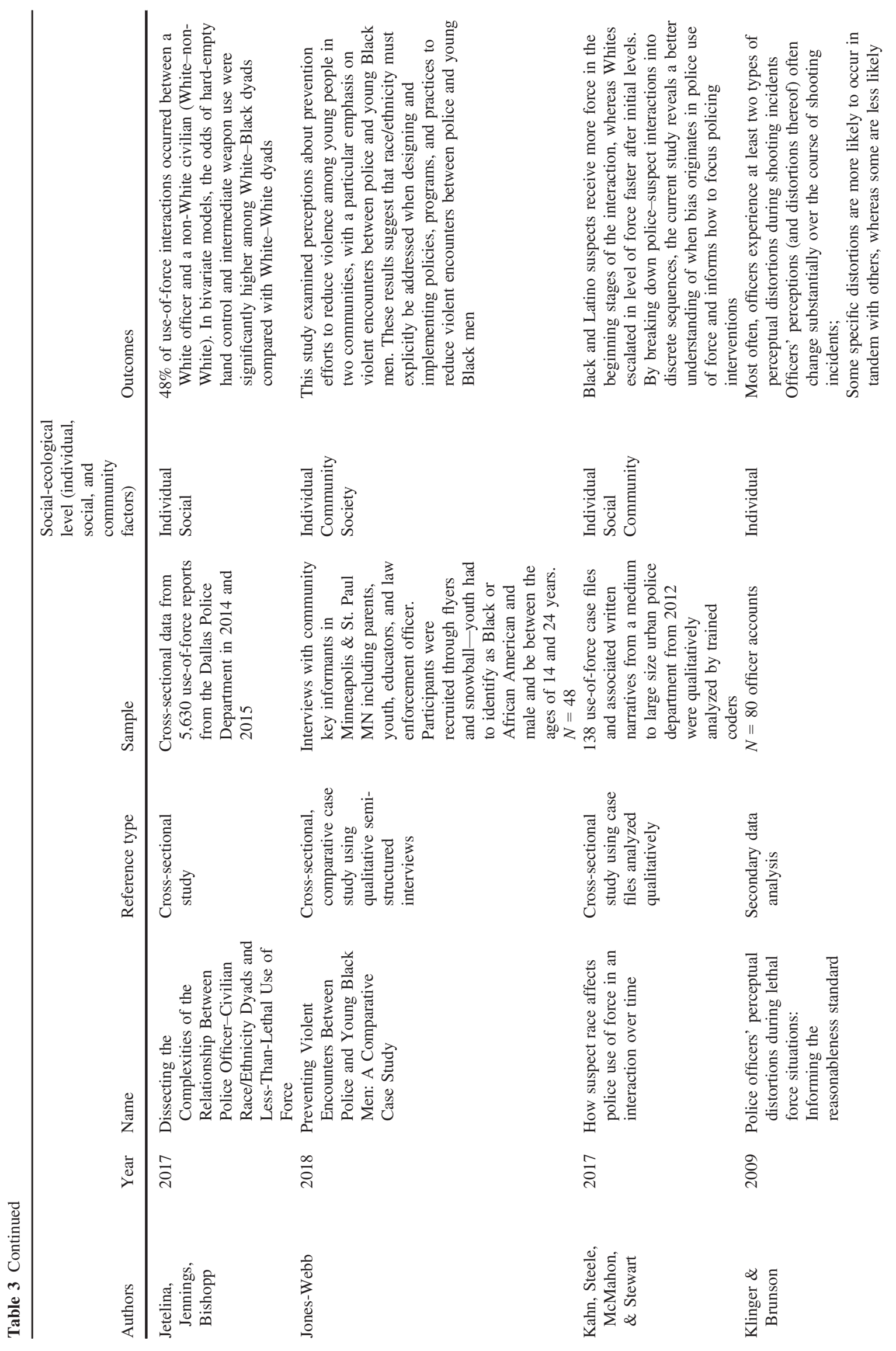




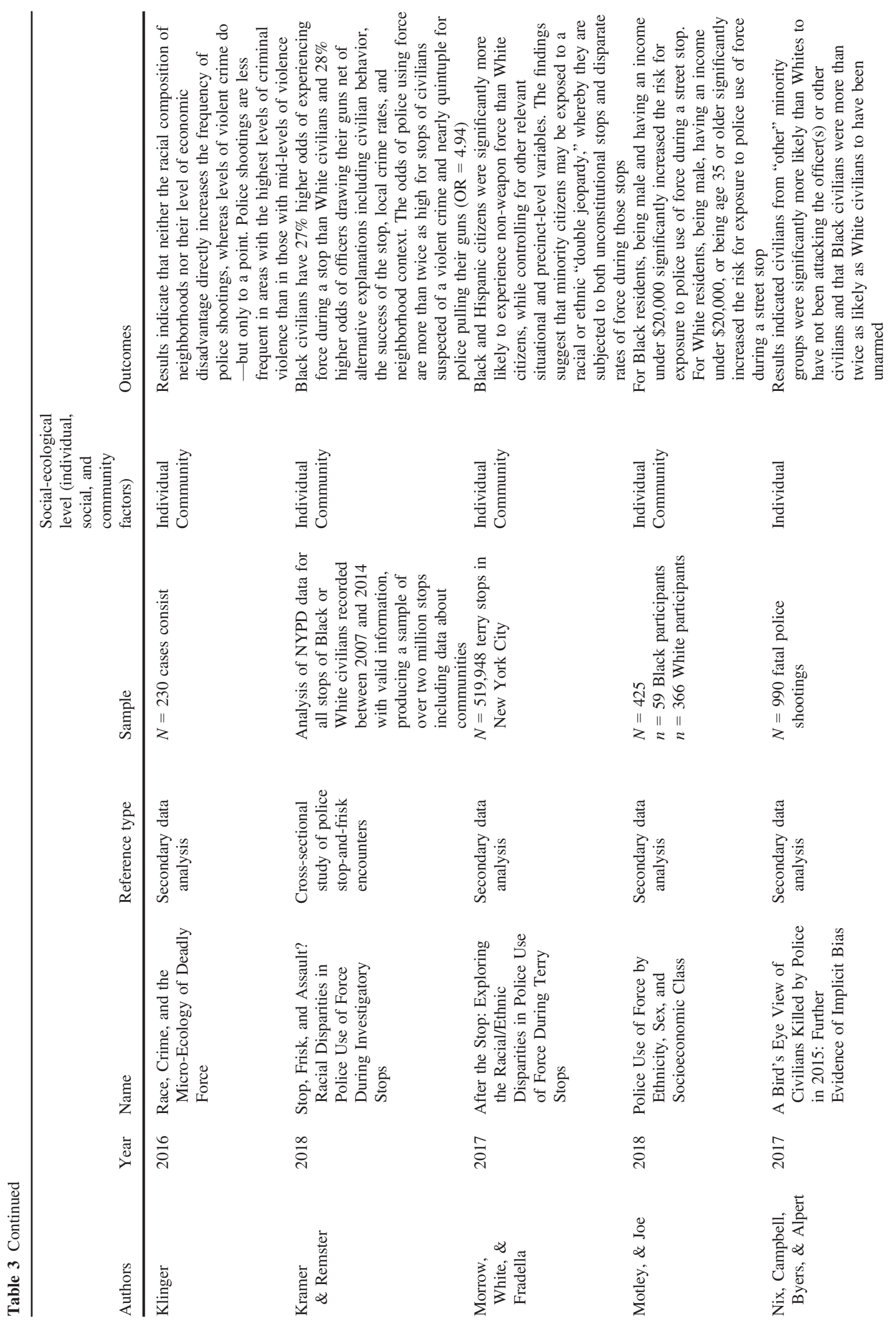




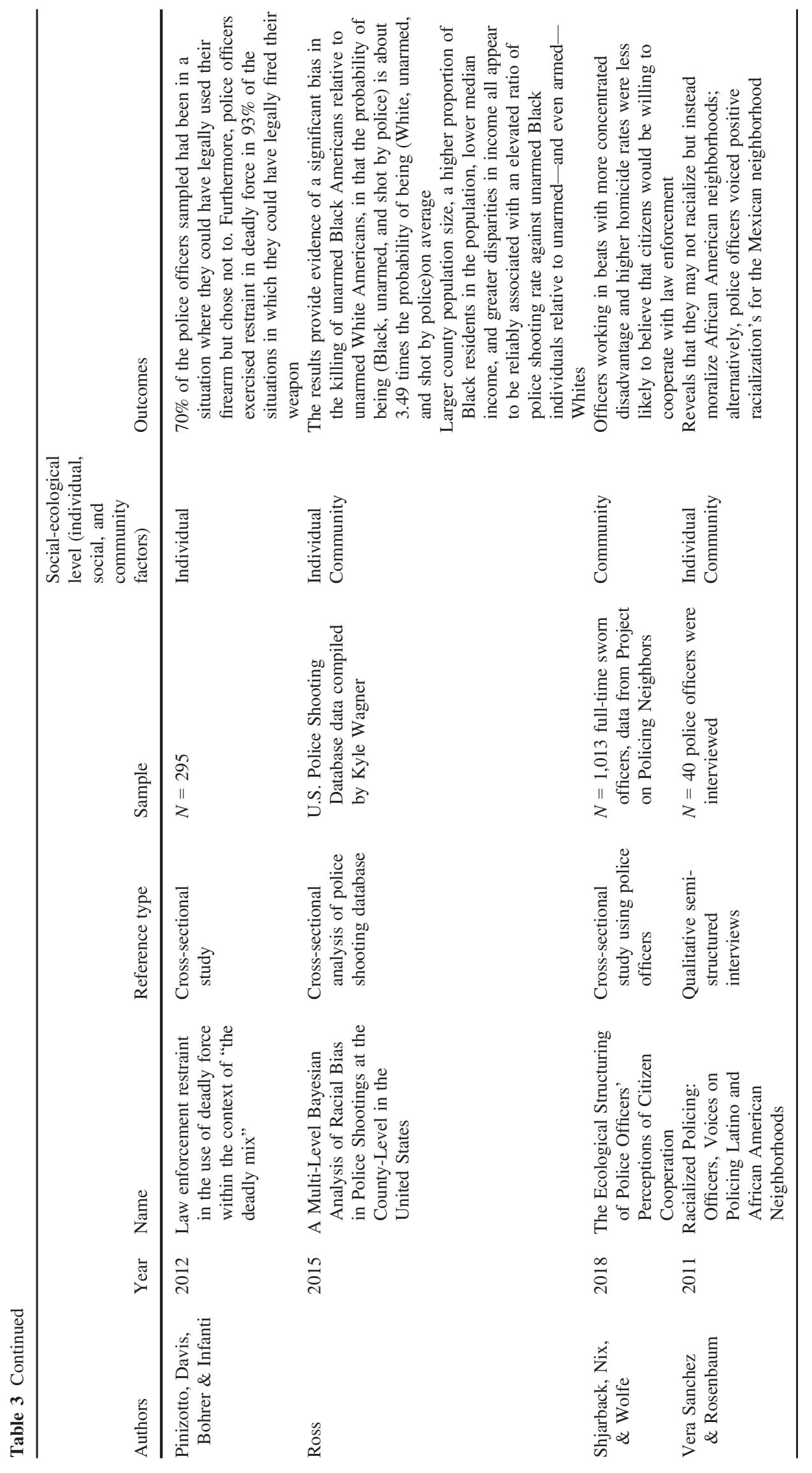


Nearly a quarter $(21 \% ; n=4)$ of studies included sociallevel factors. The studies that focused on more than the multi-level factors such as social and community found that officer relationship to the suspect, geographical location, disproportionate surveillance of people of color, and discriminatory policies were key motivating factors (Jones-Webb, Calvert, \& Brady, 2018; Kahn, McMahon, \& Stewart, 2018; Morrow, White, \& Fradella, 2017; Motley, \& Joe, 2018; Vera Sanchez \& Rosenbaum, 2011).

\section{Discussion}

This systematic review of research examined the motivating factors of police use of force in 19 studies that met inclusion criteria. This is the first such review to investigate the existing literature using the social-ecological model to understand whether studies were examining motivations at more than the individual level. We found that a majority of studies did only examine the individual level, but that some research did include a broader perspective.

\section{Contextualizing the Findings: Why Multi-Level Factors Matter}

When officers rely solely on individual factors, individuals are exposed to a racial or ethnic "double jeopardy," in which they are not only surveilled at disproportionate rates, but experience disproportionate use of force (Morrow et al., 2017). Research has shown that attitudes supportive of police violence are associated with negative cultural images of Black people (Hadden, Tolliver, Snowden, \& BrownManning, 2016a; Hadden, Tolliver, Snowden, \& BrownManning, 2016b). The demographics of the U.S. police force is $75 \%$ White and male (Hughes, Hunter, Vargas, Schlosser, \& Malhi, 2016). Hughes et al. (2016) found that police are already more likely to endorse color-blind racial beliefs, meaning that they agree with the ethos of "not seeing color." While researchers have found that the more "stereotypically Black" an individual phenotypically appears, the more likely disproportionate violence is to occur (Kahn \& Davies, 2017). Eberhardt and colleagues argue that just as "individual and situational variables shape social perception they may also shape visual perception" (Eberhardt, Dasgupta, \& Banaszynski, 2003). They further state that assigning a racial label to a face can influence one's perception of that face.

Disproportionate minority contact is a well-documented aspect of policing that occurs throughout the criminal justice system (e.g., Armour \& Hammond, 2009; Hanes, 2012; Kempf-Leonard, 2007; Piquero, 2008; U.S. Department of Justice, 2009; Huizinga et al., 2007). Research shows that exposure to Black faces facilitated the categorization of crime-relevant objects (Payne, 2001). These findings require further exploration of interventions to interrogate not only the role of individual characteristics, but also the impact of broader systems that police are nested in.

\section{Implications}

Multi-level factors affect police motivations to use force. Therefore, the systems that train and shape officers' perceptions need to be considered when designing interventions. Law enforcement training has been researched with mixed status on the effectiveness of attenuating for racial bias (Sim, Correll, \& Sadler, 2013), but there is no standardized approach for what should or should not be included to address disproportionate racial contact.

A recent study found of the police forces of the 20 largest cities in the United States, not a single department was operating under guidelines that are compliant with the minimum standards laid out under international human rights laws (University of Chicago Law School, 2020). The researchers used international sources such as the U.N. Basic Principles on the Use of Force and Firearms by Law Enforcement Officials to grade based on legality, necessity, proportionality, and accountability of use of force. For example, the U.N. Special Rapporteur states that the use of lethal force must not be arbitrary and have sufficient legal basis that complies with international human rights laws and standards. There has been a growing discussion around the effectiveness of trainings within law enforcement and if money would be better used through prioritizing social services through funding more mental health, crisis, and housing initiatives and workers. Making clear the limitations of training, according to a local Atlanta news source, the officer that killed Rayshard Brooks on June 12, 2020, had just completed a de-escalation training on April 24 and a deadly force training on January 9. Community activists have long called for the for need of various levels of change to law enforcement in response to the murder of Black people in this country. Activists from organizations including Beyond Policing and MPD150 have been calling for reprioritization, defunding, and abolishing the police.

Based on the findings from this review, addressing and deconstructing racial cues and race-based stereotypes in training is a possible first step in reform. These constructs, in particular, impact the perception of Black individuals as potential threats and influence the decision to shoot. As Hughes posits, police work attracts people who endorse color-blind racial beliefs, "not seeing color," and are reinforced throughout their career (2016). Additional research on pre-service training for new law enforcement on critical race theory and implicit bias could be beneficial as part of police recruitment. Additional research that 
examines recorded interactions of law enforcement use of force through body-worn camera video footage could elucidate the circumstances that impact an officer's decision to use force.

In order to account for the complex factors that impact implementing force, future trainings should incorporate the racial history of the United States and describe the multi-level factors that motivate "crime" with new officers. Screening tools that identify biases should also be implemented during the early hiring phases-these should incorporate the factors we know impact motivations to use increased force such as officer gender, self-control, restraint, bias, and monitoring patrol shifts at the individual level and officer relationship to the suspect, geographical location, disproportionate surveillance of people of color, and discriminatory policies at the social and community levels (Brandl \& Stroshine, 2012; Donner, Fridell \& Jennings, 2016; Hughes et al., 2016; Klinger \& Brunson, 2009; LeCount, 2017; Pinizzotto et al.., 2012; Sadler, Correll, Park, \& Judd, 2012).

The clear discrepancy between the recommendations based on the included peer-reviewed journal articles included in this review and the suggestions of community organizers highlights the importance of critical theory and community action research. Activists such as Angela Davis and Ruth Wilson Gilmore have been advocating for abolishing carceral systems, and this is mainly absent from published research. Developing evidence-based practices and interventions within institutions that are largely disconnected from on-the-ground organizing leaves academia forgoing the lived experiences and essential perspectives of those who are most often at the intersection of law enforcement and the carceral state.

Adapting the social-ecological framework to the many factors and systems that impact the decision for an officer to use force allows for a more holistic look at the complex issue. Examining factors such as race, age, gender of the suspect, and officer attributes do impact the outcome of an encounter with law enforcement, and there are larger societal factors that increase the likelihood of an individual encountering an officer who will exercise unnecessary or fatal use of force (Morrow et al., 2017; Vera Sanchez \& Rosenbaum, 2011).

\section{Limitations}

The current review and analysis have some limitations. The authors bring their own bias that has been examined through self-assessment but cannot be entirely accounted for and may influence the study search and interpretation of findings. Additionally, due to the differing nature in approaches to assess implicit bias in law enforcement use of force, statistical tests were not feasible to incorporate. Both quantitative and qualitative studies were incorporated using various designs which caused the author to approach the study analysis and synthesis through an exploratory narrative presentation of studies (Snilstveit, Oliver, \& Vojtkova, 2012). Publication bias was not addressed because the studies included were only peer-reviewed journal articles. Future research could include dissertations, unpublished work, as well as technical writing from the field.

This study also limited its search to the general reasons for law enforcement of use of force, and future research could examine the disparate impact of use of force across various racial and ethnic groups. Although there is existing literature on the disproportionate use of force on Black men in the United States, scholars like Vera Sanchez and Rosenbaum have begun to expand to include other racialized groups and additional research is necessary. Additional reviews and research should examine the intersecting experience of Black women and the use of force by law enforcement. Studies in which the setting is a controlled simulation in a laboratory lack external validity as artifacts and circumstances attempt to replicate all stressors and factors of in-the-field scenarios (James, James, \& Vila, 2016). These studies were removed but could be examined in future research.

\section{Conclusion}

Gaining a better understanding of the use of force and the motivating factors behind such force is integral in addressing the disproportionate impact on communities of color. The purpose of this study was to synthesize the existing literature to explore the motivating factors for law enforcement use of force. The social-ecological model was used to systematically examine factors that impact officer decision to use force at the individual and community levels and inform the creation of evidence-based trainings, policies, interventions, and screenings. Although individual factors such as race, age, gender of the suspect, and officer attributes do impact the outcome of an encounter with law enforcement, there are larger societal factors that increase the likelihood of an individual encountering an officer who will exercise unnecessary or fatal use of force (Morrow et al., 2017; Vera Sanchez \& Rosenbaum, 2011). We found that the officer's relationship to the suspect, geographical location, disproportionate surveillance of people of color, and discriminatory policies at the social and community levels are all key multi-level factors that go beyond individual-level perspectives to impact an officer's decision to use force (Kahn et al., 2018; Morrow et al., 2017; Vera Sanchez \& Rosenbaum, 2011; JonesWebb et al., 2018; Motley, \& Joe, 2018). However, it is 
also clear that many studies in this area narrowly focus on individual motivators - which given the current call for broad reform is too limited in scope. Future research and intervention must go beyond the individual and the conceptualization that short-term training programs will affect use of force.

\section{References}

Armour, J., \& Hammond, S. (2009, January). Minority youth in the juvenile justice system: Disproportionate minority contact. In National conference of state legislatures (pp. 1-11).

Brandl, S. G., \& Stroshine, M. S. (2012). The physical hazards of police work revisited. Police Quarterly, 15(3), 262-282.

Bronfenbrenner, U. (1979). The ecology of human development: Experiments by nature and design. Cambridge, MA: Harvard University Press.

Donner, C. M., Fridell, L. A., \& Jennings, W. G. (2016). The relationship between self-control and police misconduct: A multiagency study of first-line police supervisors. Criminal Justice and Behavior, 43(7), 841-862.

Eberhardt, J. L., Dasgupta, N., \& Banaszynski, T. L. (2003). Believing is seeing: The effects of racial labels and implicit beliefs on face perception. Personality and Social Psychology Bulletin, 29, 360-370.

Hadden, B. R., Tolliver, W., Snowden, F., \& Brown-Manning, R. (2016a). An authentic discourse: Recentering race and racism as factors that contribute to police violence against unarmed Black or African American men. Journal of Human Behavior in the Social Environment, 26, 336-349.

Hadden, B. R., Tolliver, W., Snowden, F., \& Brown-Manning, R. (2016b). Hadden.pdf. Journal of Human Behavior in the Social Environment.

Harris, C. J. (2009). Police use of improper force: A systematic review of the evidence. Victims and Offenders, 4, 25-41.

Higgins, J., \& Green, S. (2018). Cochrane handbook for systematic reviews of interventions | Cochrane training. Available from: https://training.cochrane.org/handbook [last accessed October 22, 2018]

Hanes, M. (2012). Disproportionate minority contact (OJJDP In Focus) (pp. 1-4). Washington, DC: Office of Juvenile Justice and Delinquency Prevention.

Hughes, C. E., Hunter, C. D., Vargas, P. T., Schlosser, M. D., \& Malhi, R. S. (2016). Police endorse color-blind racial beliefs more than laypersons. Race and Social Problems, 8, 160-170.

Huizinga, D., Thornberry, T. P., Knight, K. E., Lovegrove, P., Loeber, R., Hill, K. G., \& Farrington, D. P. (2007). Disproportionate minority contact in the Juvenile Justice System: A study of differential minority arrest. Referral to Court in Three Cities.

James, L., James, S. M., \& Vila, B. (2016). The reverse racism effect: Are cops more hesitant to shoot black than white suspects? James et al the reverse racism effect. Criminology and Public Policy, 15, 457-479.

Jones-Webb, R., Calvert, C., \& Brady, S. S. (2018). Preventing violent encounters between police and young Black men: A comparative case study. American journal of preventive medicine, 55(5), S88-S94.

Kahn, K. B., \& Davies, P. G. (2017). What influences shooter bias? The effects of suspect race, neighborhood, and clothing on decisions to shoot. Journal of Social Issues, 73, 723-743.

Kahn, K. B., McMahon, J. M., \& Stewart, G. (2018). Misinterpreting danger? Stereotype threat, pre-attack indicators, and police- citizen interactions. Journal of Police and Criminal Psychology, $33,45-54$.

Kempf-Leonard, K. (2007). Minority youths and juvenile justice: Disproportionate minority contact after nearly 20 years of reform efforts. Youth Violence and Juvenile Justice, 5(1), 71-87.

Klahm, C. F., \& Tillyer, R. (2010). Understanding police use of force: A review of the evidence. Southwest Journal of Criminal Justice, 7, 214-239.

Klinger, D. A., \& Brunson, R. K. (2009). Police officers' perceptual distortions during lethal force situations: Informing the reasonableness standard. Criminology \& Public Policy, 8(1), 117-140.

LeCount, R. J. (2017). More black than blue? Comparing the racial attitudes of police to citizens. Sociological Forum, 32, 10511072.

Moher, D., Liberati, A., Tetzlaff, J., Altman, D. G., \& Prisma Group (2009). Preferred reporting items for systematic reviews and meta-analyses: The PRISMA statement. PLoS med, 6(7), e1000097.

Morrow, W. J., White, M. D., \& Fradella, H. F. (2017). After the stop: Exploring the racial/ethnic disparities in police use of force during Terry stops. Police Quarterly, 20, 367-396.

Motley, R. O. Jr, \& Joe, S. (2018). Police use of force by ethnicity, sex, and socioeconomic class. Journal of the Society for Social Work and Research, 9(1), 49-67.

National Institute of Justice. (2009). The Use-of-Force Continuum. https://nij.ojp.gov/topics/articles/use-force-continuum [last accessed August 10, 2019]

Payne, B. K. (2001). Prejudice and perception: The role of automatic and controlled processes in misperceiving a weapon. Journal of Personality and Social Psychology, 81, 181-192.

Pinizzotto, A. J., Davis, E. F., Bohrer, S. B., \& Infanti, B. J. (2012). Law enforcement restraint in the use of deadly force within the context of 'the deadly mix'. International Journal of Police Science and Management, 14, 285-298.

Piquero, A. R. (2008). Disproportionate minority contact. The future of children, 59-79.

Riksheim, E., \& Chermak, S. (1993). Causes of police behavior revisited. Journal of Criminal Justice, 21, 353-382.

Sadler, M. S., Correll, J., Park, B., \& Judd, C. M. (2012). The world is not black and white: racial bias in the decision to shoot in a multiethnic context. Journal of Social Issues, 68, 286-313.

Sherman, L. (1980). Causes of police behavior: The current state of quantitative research. Journal of Research in Crime and Delinquency, 17, 69-100.

Sim, J. J., Correll, J., \& Sadler, M. S. (2013). Understanding police and expert performance: when training attenuates (vs. exacerbates) stereotypic bias in the decision to shoot. Personality and Social Psychology Bulletin, 39, 291-304.

Snilstveit, B., Oliver, S., \& Vojtkova, M. (2012). Narrative approaches to systematic review and synthesis of evidence for international development policy and practice. Journal of Development Effectiveness, 4, 409-429.

Spencer, K. B., Charbonneau, A. K., \& Glaser, J. (2016). Implicit bias and policing. Social and Personality Psychology Compass, 10(1), 50-63.

University of Chicago Law School - International Human Rights Clinic (2020). Deadly discretion: The failure of police use of force policies to meet fundamental international human rights law and standards. International Human Rights Clinic. 14. Available from: https://chicagounbound.uchicago.edu/ihrc/14 [last accessed June 19, 2020].

Vera Sanchez, C. G., \& Rosenbaum, D. P. (2011). Racialized policing: Officers' voices on policing Latino and African American neighborhoods. Journal of Ethnicity in Criminal Justice, 9, 152-178. 